\title{
Towards a Relational Understanding of the Performance Ecosystem
}

\author{
TOM DAVIS \\ Poole House, Talbot Campus, Bournemouth University, Bournemouth, BH12 5BB \\ E-mail: tdavis@bournemouth.ac.uk
}

\begin{abstract}
This article seeks to form a deeper understanding of the performance ecosystem by drawing parallels with Bourriaud's Relational Aesthetics and Guattari's conception of subjectivity as outlined in Chaosmosis. Through an examination of participation within performance, and a recognition of the mutability of the roles of performer, listener, instrument and environment in the creation of the music event, this article examines the place of subjectivity, the capacity for self-creation, in the formation of a group aesthetic. Such a concept places the creation of meaning not within the individual participant but rather within the relationship between participants in a situation, a relationship that recognises the interaction between individuals, societies and institutions in its production. Such a discussion helps further our understanding of the performance ecosystem as a conceptual tool.
\end{abstract}

\section{THE CONSTRUCTION OF THE SELF}

I think it is worth starting this article by presenting a working definition of subjectivity and the active process of subjectification. I do not intend to give an exhaustive definition of either, as their construction has long been the subject of philosophical debate. However, loosely defined, the subject can be thought of as the construction of personal and collective identities, the formulation of the self, or the construction of the I, which arises through the active process of subjectification, the process of becoming or delineating ourselves from the world.

In a 'classical' notion of subjectivity, the subjective self is seen as unitary and autonomous, a stable a priori manifestation, a pre-existing subject separate from society. Such a construction of the subjective self is indicative of the strand of philosophical (and psychoanalytical) enquiry that conceives subjectivity as having only an a priori or transcendental status, of existing autonomously and separately from our experience of the world. In contrast to this, in Chaosmosis, Guattari builds on a post-structuralist notion of the decentred subject, a formulation of subjectivity that recognises the function of interaction between individuals, societies and institutions in its creation. Guattari thus rejects the more traditional division between individual subjects and society, stating that there is no fixed instance of the subjective self; rather, it is something that is changeable, 'plural and polyphonic' (Guattari 1995: 1).

Guattari illustrates this polyphonic nature of subjectivity by considering an example of 'televisual consumption'. Stating that when he is watching television his personal identity is pulled in at least three different directions: the fascination of the 'screen's luminous animation'; the 'relation to the narrative content of the program' with a 'lateral awareness of the surroundings events' and 'a world of fantasms' occupying his daydreams (Guattari 1995: 16).

In addition to the 'plural and polyphonic' notion of subjectivity, Guattari importantly recognises the possibility of forming a collective or group subjectivity. As he states, '[w]e know that in certain social and semiological contexts, subjectivity becomes individual: persons, taken as responsible for themselves, situate themselves within relations of alterity governed by familial habits, local customs, juridical laws, etc. In other conditions, subjectivity is collective' (Guattari 1995: 9). This alterity is 'the other' against which we define ourselves, that against which we constitute our own existence. As O'Sullivan highlights, when considering the collective creation of subjectivity it is especially important to acknowledge that this otherness might itself posses a level of agency: to be aware of the fact that subjective contexts often 'interact back' (O'Sullivan 2006: 2). In addition to this, as recognised by Guattari in his discussion of machinic productions of subjectivity (Guattari 1995: 33), the otherness against which we define ourselves does not have to be human. Rather, it may consist of technological agents and cultural phenomena. The admission of non-humans as agents in the creation of subjectivity relates directly to the notion of an ecological subjectivity, a term which highlights the interdependence of each element in its construction. The self-creation and self-determination of subjectivity in this sense is described by Guattari (Guattari 1996: 195) as autopoietic in Maturana's and Varela's understanding of the word (Maturana and Varela 1980), where autopoiesis is 'a theory according to which an autonomous system creates and maintains its identity as a dynamic network of component production that builds a membrane 
or boundary between the system inside and the dynamics of the environment' (Moreno and Etxeverria 2005: 161-2). In this description all elements of the environment and subjectivity are inseparable. They can be considered co-evolutionary and structurally coupled. Such a description elevates the role of the environment, and thus the elements that constitute it, to that of active agents; agents that are involved in the construction of the self, providing 'others' against which the self might be defined.

\section{A COLLABORATIVE CONCEPTION OF MEANING}

In his text Relational Aesthetics (Bourriaud 1998) Bourriaud draws heavily on Guattari's notion of collective subjectivities in his examination of participation in the creation of a collective aesthetic object. Bourriaud illustrates his discussion with a number of artists whose work is either site-specific in nature or requires active audience participation in the creation of an event. Through this discussion Bourriaud presents an understanding of the construction of the aesthetic object as 'social interstice'; art that arises in the relationships between 'human interactions and their social context' (Bourriaud 1998: 14).

Taking an example from Bourriaud's text, what follows is a description of a work by Rirkrit Tiravanija produced for the Aperto 93 at the Venice Biennial.

A metal gondola encloses a gas ring that is lit, keeping a large bowl of water on the boil. Camping gear is scattered around the gondola in no particular order. Stacked against the wall are cardboard boxes, most of them open, containing Chinese soups which visitors are free to add the boiling water to and eat. (Bourriaud 1998: 25)

As Bourriaud notes, this work is hard to categorise. Is it a sculpture, installation or performance? What is obvious is that the spectators of the work are asked to participate in its creation, either in the physical act of adding boiling water to the soup, or through watching others do so. Bourriaud calls the people who take part 'extras' in the creation of the art (Bourriaud 1998: 26), a term that defines their role well. They are not a major part of the process but their role is essential in the creation of the work. Further, their role is an active one, one that responds to the situation as a whole. The term 'extras' recognises the bi-directional nature of the spectators' participation and recognises that they possess a level of agency in the creation of the event. The social situation of the soup-making and all the participants within it become the work.

Relational aesthetics thus comments on the shift from a conception of art that is 'situated in a transcendent world' to a conception of art that is more concerned with the 'relations existing between man and world' (Bourriaud 1998: 27). Or, as Bishop puts it: '[r]ather than a discrete, portable, autonomous work of art that transcends its context, relational art is entirely beholden to the contingencies of its environment and audience' (Bishop 2004: 54). Relational aesthetics thus examines the relationship between humans and the world in terms of art creation, focusing on the relationships between these people on a social level and their situated behaviour as perceivers.

Hopefully the parallels with Guattari's collective subjectivities are clear. Bourriaud and Guattari both foreground the social aspects of situations in the formation of subjectivity and thus aesthetic meaning. For Guattari, rather than there being a singular perceptual position from which a subjective self might be formed there is a multitude of subjective positions which are created in part by our interactions in a group, in a social setting. It is the interaction between individuals, societies and institutions that are involved in the production of subjectivity. Whereas Bourriaud's concept of relational aesthetics places the creation of meaning in a work not in the subjective experience of an individual observer but in the relationship between participants in a situation. For Bourriand, '[m]eaning is elaborated collectively rather than in the space of individual consumption' (Bourriaud 1998: 17-18).

\section{THE PERFORMANCE ECOSYSTEM}

Before I discuss the relationship between collective subjectivity, relational aesthetics and the performance ecosystem, a closer examination of the performance ecosystem itself is in order. John Bowers was perhaps the first to use the notion of the performance ecosystem as a conceptual tool, describing, in Improvised Machines (Bowers 2003), an assemblage of 'artefacts and practices' that enable him to participate in 'collective music making' (Bowers 2003: 74). Bowers likens his construction to 'Ungvary and Kieslinger's (1996)' conceptualisation of a 'musician's cockpit': a space that facilitates access to the instruments of control. This description is consistent with Bowers' presentation, at Goldsmiths College in 2004, of a number of different desktop ecologies, ${ }^{1}$ musical and non-musical, and his observation that this collection of assemblages afforded (in the Gibsonian sense) different modes of activity and methods of approach. ${ }^{2}$

Bowers' ecosystem, however, is already an extension of the aforementioned 'musician's cockpit'.

${ }^{1}$ Particularly in relation to tabletop based improvisation the notion of desktop ecologies examines how performers arrange and engage with the music-making artefacts on their desktop in accordance with their performative function.

${ }^{2}$ An experience that later led to the creation of my own desktop ecologies of performance with Jason Dixon. 
Crucially, he augments his assemblage of tools with practices of laptop improvisation and the social and musical context of participation in 'collective music making'. He sees his improvised music as exploring the contingencies of live performance: 'notions of musical gesture, interaction, texture, interruption, performance as an embodied practice, 'emergent' instruments, the relationship between electronic and acoustic sound sources, physical models and metaphors in music and so forth' (Bowers 2003: 2).

One instance of this is Bowers' continuous twelvehour electroacoustic improvisation in Ipswich in 1999 (with Sten-Olof Hellstrom), during which the public were free to come and go at will, moving around a performance space set with a number of different performance stations. At each performance station was a variety of instruments - a number of different autonomous installations, algorithmically generated control data, video-generated algorithmic music and detuned radios - all of which had points for disruption and intervention, such that they could be left to generate audio autonomously or performed with in a more active manner. As Bowers states, the performers worked to 'assemble a manageable environment for extended improvised electroacoustic music' (Bowers 2003: 29). With his assemblages of interactive devices throughout the space and a level of openness to the audience I see Bowers' practice as intrinsically grounded in the larger ecosystem of performance: one that includes the other performers, the performance context and the social dimensions of 'collective music making' (Bowers 2003: 74).

Simon Waters, in his 2007 paper 'Performance Ecosystems: Ecological Approaches to Musical Interaction' (Waters 2007), further develops these implied references to environmental and social contexts by describing a conception of a performance ecosystem that problematises the 'self-evident' boundaries between performer, instrument and environment, recognising the often interpenetrating agency of each component of the performance. In this article Waters examines what is lost by the habitual separation of these terms and explores what is to be gained through a re-examination of their boundaries. Waters states that he developed his understanding of the performance ecosystem in order 'to counter a sense that those who compose or perform, particularly in highly technologised environments, are wont to celebrate the technological, and to be reductive about (or at least less attentive to) the nature of music as an activity (as practice) - tending to consider the acoustic fact at the expense of social and cultural context' (Waters 2007: 1).

It is this idea of music as practice that I think is worth further exploration, as it is this active consideration of music-making that underpins the understanding of the performance ecosystem. Waters starts his 2007 article with a quote by Jonathan Impett, which bears repeating here.

Music is understood as a dynamical complex of interacting situated embodied behaviours. These behaviours may be physical or virtual, composed or emergent, or of a time scale such that they figure as constraints or constructs. All interact in the same space by a process of mutual modelling, redescription, and emergent restructuring. (Impett 2001: 1)

This understanding of music highlights its ephemeral nature as something that evolves amongst a complexity of interacting parts in a durational manner such that the object of music creation is situated and timely. Particularly in improvisational contexts (and arguably in all music) one can argue that the musical object is that which is created in the interaction between performer, instrument, environment and audience. The performance ecosystem thus represents the dynamical and emergent structural characteristics that form in the moment of encounter - in the social interaction found in collective music-making.

As Barthes notes in 'From Work to Text', in the history of music 'there was a period when practising amateurs were numerous (at least within the confines of a certain class) and "playing" and "listening" formed a scarcely differentiated activity' (Barthes 1977: 163). This is echoed by Christopher Small's concept of musicking (Small 1998: 9), in which both performers and listeners are considered active in the performance of the musicmaking event. Small, however, goes on to extend this definition, stating that if 'musicking is an activity by means of which we bring into existence a set of relationships that model the relationships of our world ... then musicking is in fact a way of knowing our world not the pre-given physical world, divorced from human experience that modern science claims to know, but the experiential world of relationships in all its complexity' (Small 1998: 50). If we view music creation as a participatory act that reflects the social act of being in the world and the timely dimensions of perceiving the world (as we do in the performance ecosystem) then the confluence with relational aesthetics is hopefully self-evident.

This understanding of music creation has obvious links with the way the art object is structured within the traditions of Dadaism, Cage's indeterminate compositions, the happenings of Fluxus and Joseph Beuys' 'social sculpture'. Such works present a scenario within which one interacts. In the same way, the performance ecosystem creates a field of possibilities for interaction: a field that crystallises or collapses into the performance through the interaction of the interdependent elements of audience, performers, instruments and environment.

In my own practice as an improviser, performing with Jason Dixon as part of the duo JDTJDJ, I have 
been interested in making works that evolve through the generation of performance ecosystems that consist of numerous disparate elements. Inspired by Bowers, we create our own desktop ecologies of devices, such as hacked instruments, computer-based algorithms, appropriated objects (coffee cups, hat stands) and feedback loops, which connect the desktop ecologies directly to the performance context. In this fashion we work with a myriad disparate elements that can come together in a number of often unpredictable ways in the creation of the performance. The ecosystem is created through the choice of performance objects but also by their use in a live performance: there is interaction between performers, between performers and audience, and between performers and site. There is a social interaction between all: an interaction that leads to a construction of a shared notion of performance.

\section{MUSIC AND OBJECTHOOD}

What the artist produces first and foremost, is relations between people and the world, by way of aesthetic objects. (Bourriaud 1998: 42)

For Guattari, it is specifically in the process of art creation that individuals find themselves 'enveloped by a number of transversal collective identities' or 'situated at the intersection of numerous vectors of partial subjectivation' (Guattari 1996: 98). As Bishop states: "[f]or Guattari, art is a process of "becoming", a fluid and partially autonomous zone of activity that works against disciplinary boundaries, yet which is inseparable from its integration in the social field' (Bishop 2006: 79).

Art then, or, for the purposes of my argument, music as practice, creates a site for experimentation, a site for spectatorship, a site for active collaboration in the act of creating, a scenario of participation in which one can lose and renew oneself. Participating in music furthers one's relationship to, and understanding of, the world as a site for exploring changed subjectivities. For Guattari, participation in art creation is a way of re-defining the participant in a subjective and aesthetic sense. This encounter, described by Guattari as a 'rupture', 'cut' or 'fragmentation', 'can be at the very origin of mutant centers of subjectivation' (Guattari 1996: 200).

If we accept a social description of music that is built on participation, on relations between the elements of an ecosystem, as something that is constructed in 'social exchanges $\ldots$ in the collective production process' (Bourriaud 1998: 41), what then becomes of the aesthetic object in this context?

In Image Music Text Barthes distinguishes the work, an 'object of consumption', from the text, a 'structured but decentred network' of irreducible plural meanings. Importantly for Barthes, the 'text' can only be experienced in 'an activity of production' (Barthes 1977: 157). The listener is thus constructed as an active participant in the creation of the work rather than a passive consumer of it. Barthes helpfully situates his discussion in the field of music by stating that, in post-serial music, rather than interpreting the score to give it 'expression', the performer/ listener completes the score as a co-author of the work, as co-author of the aesthetic object. This can be linked to the performativity of art at which Fried expressed dismay in his 1967 writing, Art and Objecthood (Fried 1967). Fried was upset by the 'theatricality' of this art, which he saw as marked by 'duration' rather than the 'transcendental instantaneousness' that he saw as proper to the condition of beholding visual art. He felt that the autonomy of the art object itself was threatened, as the object was now contingent on space, place and cultural context. $\mathrm{He}$ also felt that the purity of each artistic medium was under threat.

Whilst minimalist sculpture has often been interpreted in a phenomenological fashion, regarding the work as an encounter with an embodied perceiver, the phenomenological tradition is founded on the process of the reduction of the subject in order to study a singular response to the world through an individuated perception of it. However, as Bourriaud states: '[m]inimalism addressed the question of the viewer's participation in phenomenological terms. The art of the ' $90 \mathrm{~s}$ addresses it in terms of use' (Bourriaud 2001). Art, in this sense, does not exist through a singular reductive perception; rather, its meaning is elaborated collectively through the elements of its construction.

In the case of music, especially when music is understood as practice, there is arguably no aesthetic physical object. Music is inherently ephemeral and durational: a dynamic process that takes into account the performer/listener relationship and recognises the act of participation in the creation of the aesthetic. The aesthetic object of music insofar as it exists is only created in the performance, in the field of production/ consumption that takes into account every element of its performance. The performance ecosystem thus foregrounds and recognises the construction of the aesthetic object as a timely act that is situated in an ecology; an ecology that involves all the agents in its construction, be they human, environmental or technological.

With this lack of physical object, music lends itself to a description of aesthetic creation that evolves as an encounter between musicians, audience, instruments (both technological and non-technological) and environment. The spectator is thus given an equal role in the creation of the object. Beyond Barthes' notion that spectators re-create the work in re-interpreting it, rather I suggest here that they actually create the work through participation in spectating. As Ranciere states, the emancipation of the spectator starts with 
the principle of equality, with the recognition that 'interpreting the world is already a means of transforming it' and that ' $[\mathrm{t}] \mathrm{h}$ e spectator is active, just like the student or the scientist: he observes, he selects, he compares, he interprets' (Ranciere 2007: 277).

The work of art, then, is an opportunity for a redefinition of the self as it creates the opportunity for an 'activity of unframing, of rupturing sense, of baroque proliferation or extreme impoverishment, which leads to a recreation and a reinvention of the subject itself' (Guattari 1996: 131). It is this very 'unframing' that leads to a 'resingularisation' of the subjective self. This is a testament to the power of art. Art not only changes our perception of our surroundings but also alters the subject, engendering change within ourselves: it recognises that, although we change through our observations of the world, in observing the world we also change it.

\section{FINAL REMARKS}

The performance ecosystem examines music as practice, music that is formed in the moment in the act of performance. Stemming from its construction as an assemblage of artefacts and practices to facilitate collective music creation, the performance ecosystem provides a site of possibilities for action that collapse into singular realities in the moment of performance. Music as practice is an active consideration of music formation such that the listeners are given an active role in the process of music creation, much as Guattari's active process of subjectification invites us to move from the position of passive spectatorship to that of active participation. In the same way, it provides an opportunity for people to go beyond their normal experience - extending their view of the world. The social aspects of music-making reflect the sociality of life; this interaction provides a place for subjects to redefine their essence of beingin-the-world through a creation of themselves that is effected by the location and their activity within it: through a resingularisation of subjectification.

This article is one practitioner's attempt to formalise an understanding of the performance ecology's relationship to relational aesthetics by examining the subjectivity of the performers and their relation to aesthetic production. It draws a link between the social aspects of music-making, the idea that art is created from social exchanges and the site of music creation as a special place for the process of collective aesthetic production. It promotes an idea of music as a space for 'dialogue ... discussion ... and inter-human negotiation’ (Bourriaud 1998: 41).

\section{REFERENCES}

Barthes, R. 1977. Image Music Text. London: Fontana Press. Bishop, C. 2004. Antagonism and Relational Aesthetics. October 110: 51-79.

Bishop, C. 2006. Participation. London: Whitechapel.

Bourriaud, N. 1998. Relational Aesthetics. Dijon: Les presses du réel.

Bourriaud, N. 2001. Public Relations: Bennett Simpson Talks With Nicolas Bourriaud, Artforum (April 2001). Available at http://www.findarticles.com/p/articles/mi m0268/is_8_39/ai_75830815 (accessed 20 April 2011).

Bowers, John. 2003. Improvising Machines: Ethnographically Informed Design for Improvised Electro-acoustic Music. Available at http://www.ariada.uea.ac.uk/ariadatexts/ ariada4 (accessed 27 October 2006).

Fried, M. 1967. Art and Objecthood. In C. Harrison and P. Wood (eds), Art in Theory, 1900-1990: An Anthology of Changing Ideas. Oxford: Blackwell, 2000.

Guattari, F. 1995. Chaosmosis: An Ethico-aesthetic Paradigm, trans. P. Bains and J. Pefanis. Sydney: Power Publications.

Guattari, F. 1996. Subjectivities: For Better and for Worse. In G. Genosko (ed.), The Guattari Reader. Oxford: Basil Blackwell, 193-203.

Impett, J. 2001. Interaction, Simulation and Invention: A Model for Interactive Music. In E. Bilotta, E.R. Miranda, P. Pantano and P.M. Todd (eds), Proceedings of ALMMA 2001 Workshop on Artificial Models for Musical Applications. Cosenza: Editoriale Bios, 108-19.

Maturana, H. and Varela, F. 1980. Autopoiesis and Cognition: The Realization of the Living. Netherlands: Reidel Publishing Company.

Moreno, A. and Etxeverria, A. 2005. Agency in Natural and Artificial Systems. Artificial Life 11(1-2): 161-76.

O'Sullivan, S. 2006. Academy: The Production of Subjectivity. In Irit Rogoff et al. (eds), Academy. Frankfurt: Revolver.

Ranciere, J. 2007. The Emancipated Spectator. Art Forum (March): 270-81.

Small, C. 1998. Musicking: The Meanings of Performing and Listening. Middletown, CT: Wesleyan University Press.

Ungvary, T. and Kieslinger, M. 1996. Towards a Musician's Cockpit. Proceedings of the International Computer Music Conference. Hong Kong.

Waters, Simon. 2007. Performance Ecosystems: Ecological Approaches to Musical Interaction'. Proceedings of the Electroacoustic Music Studies Network 2007. http:// www.ems-network.org/spip.php?article278. 